\title{
Exploring the occupational engagement experiences of individuals with oculocutaneous albinism: an eThekwini District study
}

\author{
*Lara Mather,** BOT (UKZN). http://orcid.org/0000-0002-0365-795 I \\ Community Service Occupational Therapist - Rietvlei Hospital
}

Thavanesi Gurayah, BOT (UDW), MOT (UKZN). http://orcid.org/0000-000 I-9005-6355

Lecturer, Discipline of Occupational Therapy, School of Health Sciences, University of Kwa-Zulu Natal

Deshini Naidoo, BOT (UDW), MOT (UKZN), PhD (UKZN). http://orcid.org/0000-000 I-6276-22 IX

Lecturer, Discipline of Occupational Therapy, School of Health Sciences, University of Kwa-Zulu Natal

\section{Henna Nathoo,** BOT (UZKN) http://orcid.org/0000-0002-09 I 6-6299}

Community Service Occupational Therapist -Dr Yusuf Dadoo Hospital

Fortune Feresu,** BSc (IU), B OT (UZKN) http://orcid.org/0000-0002-26 I7-555X

Nhlanhla Dlamini,** BOT (UZKN) http://orcid.org/0000-0003-4384-7343

Community Service Occupational Therapist - Ndwedwe CHC

Trinity Ncube, $* *$ BOT (UZKN) http://orcid.org/0000-0002-9496-602X

Zuleika Patel,** BOT (UZKN) http://orcid.org/0000-0002-9155-2833

Community Service Occupational Therapist - Cato Manor CHC

\section{**Fourth year students in Discipline of Occupational Therapy, School of Health Sciences, University of KwaZulu-Natal at the time of the study}

Background and aim: The World Federation of Occupational Therapists' urges occupational therapists to recognise when people are being denied the right to participate in occupations and advocate for change. People with oculocutaneous albinism face stigma and discrimination owing to mythical beliefs surrounding the condition. This may negatively affect their engagement in occupations. Therefore, this study aimed to explore the occupational engagement experiences of individuals with oculocutaneous albinism within the eThekwini district.

Method: A qualitative research design, using a phenomenological approach, was chosen to explore the participants lived experiences. Five participants were recruited using snowball sampling. Semi-structured interviews were used to obtain data which was analysed thematically.

Results/ Findings: Data collected yielded three major themes: sense-of-self, barriers to occupational engagement and facilitators to occupational engagement. Four participants demonstrated a positive self-identity, which supported occupational engagement and aided the individual in overcoming barriers. Reasonable accommodations, social- and structural support facilitated occupational engagement, whilst myths and beliefs, physical limitations and the physical environment formed barriers to occupational engagement.

Conclusion: A new finding that emerged, indicated a change in self-perception, with participants adopting positive self-identities that facilitated occupational engagement. This may be attributed to participants belonging to the millennial generation, which is considered open-minded and deviating from tradition.

Key words: Albinism, occupational engagement, barriers and facilitators to occupation. eThekwini District, KwaZulu-Natal, South Africa.

\section{INTRODUCTION}

Oculocutaneous albinism (OCA) refers to a group of biologically inherited disorders characterised by a melanin deficiency, which affects pigmentation in the hair, skin and eyes'. Within the South African context, individuals with OCA are considered a minority group who face ongoing discrimination despite constitutional law ${ }^{2}$.
Although South Africa is a country that considers its constitution one of the most progressive in the world, beliefs and attitudes towards albinism are still deep-seated within traditional belief systems ${ }^{3}$. The perceptions of individuals living with OCA stem from a lack of knowledge pertaining to the genetic epidemiology of the condition, and these manifest both in self-stigma and stigma from the 
community ${ }^{4}$. Implications resulting from the overt discrimination and stigma directed at the person living with OCA, such as social isolation and emotional instability, have the potential to directly impact engagement in social activities and daily occupational tasks'. Occupational engagement not only serves to bring meaning and purpose to life, but also contributes to communities' view of an individual $^{5}$. This article will explore how having OCA affects the individual's ability to participate in their meaningful daily occupations, particularly within the eThekwini district.

\section{BACKGROUND}

Oculocutaneous albinism is characterised by several physical limitations, such as impaired eyesight and a melanin deficiency with a lack of cutaneous, pilar and ocular pigmentation from the time of birth. Physical attributes associated with OCA are distinct and unusual owing to the evident white skin tone and lack of colour in the eyes and hair ${ }^{6,7}$. Myths and beliefs surrounding OCA have great potential to influence society's attitude towards individuals living with OCA, and, as a result, may impact their ability to optimally interact within social contexts ${ }^{8}$. Myths and beliefs can perpetuate the development of societal- and self-stigma, wherein individuals accept and internalise the views of other members in society ${ }^{8}$.

Brilliant ${ }^{9}$ described myths as being the main causal factor of culturally-driven traditional practice, murders and mutilations amongst the albino population. However, less documented is the positive mythical interpretations of individuals with OCA, such as in their ability to bring luck to those who come into physical contact with them $^{10}$. This results in the individual with OCA being held in high regard, protected and endorsed with monetary and material items ${ }^{10}$. Anecdotally, the above factors may influence the individual's ability to engage in various occupations and roles. Literature predominantly focuses on the congenital characteristics associated with OCA, as well as the mythical connotations that are underpinned by the physical characteristics ${ }^{6}$ and there has been no research exploring individuals with OCA's ability to engage in meaningful occupations. Wilcock and Hocking ${ }^{5}$ report a link between health, well-being and participation in occupations. The World Health Organisation (WHO) states that wellness is based upon the individual obtaining their maximum potential of physical, psychological, social, spiritual and economic development and fulfilment of role expectations in family, community, workplace and other settings ". The WHO further stated that people need to be able to satisfy their needs and cope with their environment in order to reach a state of health and well-being. Being denied or prevented from the opportunity or being unable to engage in meaningful occupations can have a negative effect on a person's health ${ }^{5}$. Considering the view that engagement in occupation is a human right and not just a health issue $^{5}$, it is imperative that occupational therapists analyse any potential barriers as well as facilitators to occupational engagement for individuals with oculocutaneous albinism ${ }^{4}$.

\section{METHOD}

This study used a qualitative study design, as the aim was to generate an understanding of the lived occupational engagement experiences of individuals with oculocutaneous albinism using an interpretative phenomenological approach ${ }^{12,13}$.

\section{Sampling}

The study was set in KwaZulu-Natal, eThekwini district. Purposive snowball sampling was used to recruit five participants. The first participant was known to the researchers and referred potential participants who were sent information regarding the research. Inclusion criteria included a confirmed diagnosis of oculocutaneous albinism, the participant had to be between the ages of 18 and 65 and be a resident of eThekwini for at least one year. These inclusion criteria allowed for the selection of participants with a wider range of occupations which included work and higher education.

\section{Data Collection}

A semi-structured interview schedule was formulated using the occupational justice framework. The questions were formulated using the areas in the occupational justice framework noted to facilitate or hinder participation in occupation. The prompts for the interview questions referred to values, culture, policies, physical and social environment that either hinder or facilitate engagement in occupation. The questions were tested in a pilot study with a person known to the researchers who met the inclusion criteria. The questions yielded sufficient information to answer the research question, however minor adjustments were made to reduce ambiguity.

Five single, 60 minute individual semi-structured interviews were conducted in English and IsiZulu with a translator. Semistructured interviews were advantageous, as this data collection method allowed for dynamic engagement between the researcher and participant, enabling clarity, understanding and reflection, which were vital in establishing an open communication channel ${ }^{13,14}$. Interviews were audio-recorded with permission from participants, and fieldwork observations were noted. Interviews were conducted at venues that were convenient for each participant.

\section{Data Analysis}

Audio-recordings were transcribed verbatim. Braun and Clark's ${ }^{15}$ thematic analysis was used to analyse data, which allowed for identification, thorough analysis and description of the themes from the data collected. The researchers immersed themselves within the data, reading and re-reading the transcripts. Initial codes were generated inductively through each researcher who individually highlighted key phrases. The highlighted phrases were then discussed until a consensus was reached. The initial codes were reduced into categories which were then grouped together to form themes.

\section{Trustworthiness}

Credibility was ensured through peer debriefing and researcher analyst triangulation. Member checking was completed after transcription of the verbal data to ensure veracity. Thick description ensured transferability. An audit trail was used to ensure dependability. The researchers' used reflexive journaling to reduce any potential bias.

\section{Ethics}

Permission was obtained from the Humanities and Social Science Research Ethics Committee at the University of Kwa-Zulu Natal (protocol reference number HSS/0I45/0I9U). Information handouts and informed consent forms were distributed once individuals had voluntarily agreed to participate. At the interview, participants were informed of confidentiality, ethical responsibilities of the researchers, the right to use pseudonyms and the right to withdraw. Informed consent for audio-recording and field notes were obtained using consent forms.

\section{FINDINGS}

The demographics of the participants (Table I p54) indicated two participants were students at a university, whilst three were permanently employed. All participants were African and unmarried, 
Table I: Demographics of participants

\begin{tabular}{|l|l|l|l|l|l|l|}
\hline Pseudonyms & Age & Race & $\begin{array}{l}\text { Marital } \\
\text { status }\end{array}$ & Children & $\begin{array}{l}\text { Level of } \\
\text { education }\end{array}$ & Employment \\
\hline Derek & 24 & African & Single & 0 & $\begin{array}{l}\text { Honours } \\
\text { Degree }\end{array}$ & Retail \\
\hline Victor & 27 & African & Single & I & Diploma & Porter \\
\hline Thandi & 23 & African & Single & 0 & $\begin{array}{l}\text { Under- } \\
\text { graduate }\end{array}$ & Student \\
\hline Vee & 23 & African & Single & 0 & $\begin{array}{l}\text { Under- } \\
\text { graduate }\end{array}$ & Student \\
\hline Bob & 31 & African & Single & 0 & $\begin{array}{l}\text { Honours } \\
\text { Degree }\end{array}$ & Call centre \\
\hline
\end{tabular}

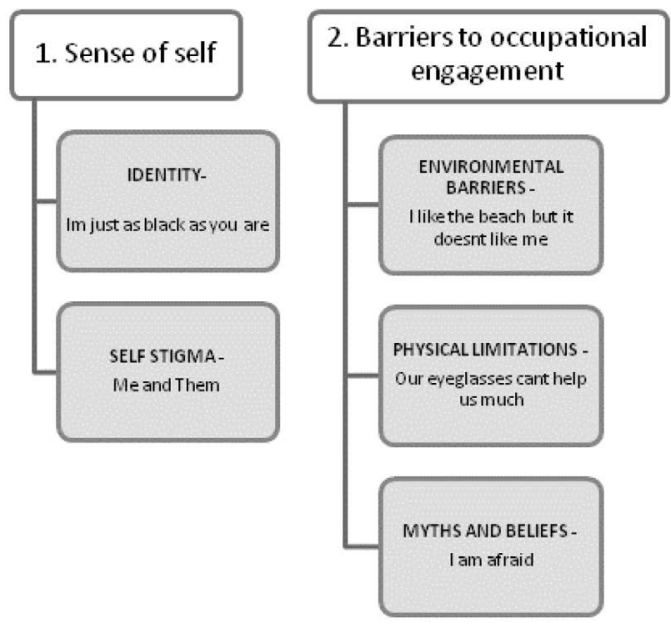

Figure I: Themes

with two participants being female and three of the male gender.

The data collected revealed three major themes. The first theme described the manner in which the participants viewed themselves, revealing their sense-of-selves. The second theme identified barriers to occupational engagement, whilst the third theme identified facilitators to occupational engagement. These will be outlined below with verbatim quotes to illustrate the themes (Figure I).

\section{Theme I: Sense-of Self}

This theme contained two contrasting sub-themes namely Identity: I'm just as black as you are, and Self-stigma: me and them.

\section{Identity: I'm just as black as you are}

Findings indicated that participants correlated their acceptance of themselves and their positive self-identity as the reason for their acceptance by society and their communities.

Having this personality helps the way people treat me everywhere, not just in the workplace (Bob, 3I, employed).

Participants indicated that their positive self-identify developed because of parental acceptance. Moreover, they indicated that extra-mural activities such as scouts promoted the development of a positive self-identity, as well as the establishment of values that promoted positive self-identity. Sense of self culminated in the realisation that acceptance and a positive view of self, originated from the understanding that physical factors were not self-defining, and that identity was based on the portrayal of self.

When you already accept that l'm different, just that my skin colour is different and my needs are a little bit different than the next persons', you can live positively. (Vee, 23, student).

\section{Self-Stigma: Me and Them}

Participants spoke of me and them as a differentiating concept between themselves and those whom the participants considered as "normal". From the concept of othering, the participants expressed a sense of self that reflected self-stigmatising views. This was expressed by adopting a self-identity that reflected derogatory terms associated with albinism. The implications of self-stigma predominantly affected the area of social participation.

Those people will not recognise you, because he didn't know or she didn't know the pain that you have, but it's better if you are helped by someone with a disability, because he/she knows the suffering of being disabled (Victor, 27, employed).

\section{Theme 2: Barriers to occupational engagement}

This theme comprised of three subthemes, namely environmental barriers: I like the beach but it doesn't like me, Physical limitations: our eyeglasses can't help us much, and Myths and beliefs: I am afraid.

\section{Environmental Barriers: I like the beach but it doesn't like me}

The findings yielded several environmental barriers that limited engagement in various areas of occupation. Evidence of this surfaced in the participants who were engaged in work which included bright, harsh lights that further compromised their eyesight. Environmental barriers were not only limited to workplace settings, as participants explained that the intensity of the sun presented as a barrier when engaging in outdoor activities. The implications of the participants' exposure to the intensity of the sun had the potential to limit occupational engagement, as well as the propensity to result in adverse health implications, such as skin cancers.

The only thing that I liked, really liked, was soccer 'cause I was a bit of a tomboy growing up. But then the sun, so I can't like play at twelve, so it was something I liked doing and couldn't (Thandi, 23, student.)

I never played sports in school, cause of my skin colour... I used to get sun-burnt bad (Thandi, 23, student).

If the weather is 32 degrees I can't say 'guys I will be sunburnt'.. normally I will come back with me sunburnt (Thandi, 23, student). 
It's easy to be affected or to get cancer when you are not using body lotion... you must look at the weather... when you see its 31 degrees today, you must use $50 \%$ lotion because that means the sun is high. (Bob, 31 , employed).

\section{Physical limitations: Our eyeglasses can't help us much}

Limitations associated with the congenital features of oculocutaneous albinism emerged as barriers to occupational engagement among the participants. Owing to a lack of melanin within their skin and eyes, they experienced physical limitations such as extreme hypersensitivity to light, as well as visual impairments. The limitations specifically affected the participants' performance in areas within places of education, work and pertaining to social participation and leisure. Barriers to scholastic engagement caused by impaired eyesight were emphasised by the lack of accommodations within mainstream schools. However, the university offered reasonable accommodations, which served as a facilitator to learning, however this simultaneously acted as a barrier to social participation. For instance, lecture notes were printed and made available to the participant to compensate for her impaired vision; this resulted in hostile sentiments between the participant and her peers, as she was not permitted to share the notes with other learners.

It was in two tutorials that I just didn't know what was going on because the tutor was writing on the board (Thandi, 23, student).

[The lecturer] He emailed me the slides and told me not to share... I am in class and the slides are open on my laptop... everybody sees I have slides... now I cannot share them [the slides] with them (Thandi, 23, student).

Impaired eyesight also impacted workplace experiences, where two of the three employed participants expressed challenges in performing their worker roles. In addition, participants explained that being sensitive to the sun posed adverse health risks, which directly impacted their engagement in leisure activities and social participation.

You need to be vigilant; you need to see what's happening. You need to pay attention to any transaction when you want to grow, you are required to work the till, my eyesight is bad and the till is fragile, it's very scary. I was going to be seen as a nuisance, you know, because first of all I can't see clearly there is too much lighting (Derek, 24, employed).

When you see the lights at the hospital, they are so bright, so we don't deserve to be in the place that is bright, because our eyes get affected (Victor,27, employed).

When I come from indoors from being in the sun after a while I get a migraine (Thandi, 23, student).

\section{Myths and beliefs: I am afraid}

Myths and beliefs are rooted within traditional beliefs and rituals, and particularly within community settings. The participants shared that they were called derogatory names within a social setting, which was attributed to societies' myths and beliefs surrounding individuals with albinism. Participants expressed that their fear within community settings originated from the association of albinism and traditional rituals, resulting in the development of feelings of vulnerability to harm. Vulnerability emanated from the myth that individuals with albinism bring good luck. This faulty belief was seen as the driver for the fatal repercussions of these beliefs, when people with OCA are murdered, or their body parts used for "muti" (traditional medicine). Further effects extended into intimate relationships, where strangers expressed a desire to engage in sexual activities with three of the participants, due to these mythical beliefs.

There was this mom and this lady was with her kids, three kids, and they were like 'hawu, sawubona umlungu, sawubona umlungu (derogatory name for white person). The mom said, 'ay, it's better they calling you umlungu, they didn't call you isishawa (cursed)" (Vee, 23, student).

I wasn't allowed to go outside on the road especially, I wasn't allowed to travel alone, I had to travel with an adult (Derek, 24, employed).

Let me make this clear, I'm afraid to go alone, I prefer to go with a person who I have a relationship with, like my friend or my family so that when something happens, I can know who can look after me (Victor, 27, employed).

When you go outside, people give you money, they say 'ay, please pray for me, you bring good luck' and then that person, that random person just approaches you and gives you money (Vee, 23, student).

They believe when you are born with albinism, luck is around you. You become rich. So that is why in Central Africa, people with albinism are being slaughtered and their parts are being sold to sangomas (Vee, 23, student).

Like people randomly say they wanna sleep with me or stuff; you know things like that (Thandi, 23, student).

\section{Theme 3: Facilitators to occupational engagement}

This theme comprised of four subthemes, namely Social support: She took it upon herself to train me while others were... too tired, Coping mechanisms: Escape from the real world, Structural support: Different people need different things and Reasonable accommodations: I can't read print that is too small or too light.

\section{Social Support: She took it upon herself to train me while others were... too tired}

Social support emerged as a common factor that supported four out of the five participants' engagement in occupations. Four participants mentioned the church as an area of occupational engagement, with one participant expressing a strong presence of his church community in his life, as well as a social support network in the workplace.

They are like my second family, if I may say, those beliefs, they just check up on me 'cause you know in the news you hear this and that. They just check up on me. Others even come here and check up on me (Derek, 24, employed).

Even though only one participant specifically named his church community and work colleagues as forms of support, three other participants highlighted the presence of supportive people in their lives as a system that enabled them to engage in occupations. Participants expressed that the relationship and support received from 
family members facilitated occupational engagement.

I owe her a lot. She is the one who took it upon herself to train me while others were, I don't know. I'm looking for this word, too tired (Derek, 24, employed).

If I am home or like say if am leaving home my brothers accompany me to the taxi rank so they just leave me in a taxi they know am safe in a taxi what happens that side (Thandi, 23 student).

Well my father was my major support system, if I may say. Because, as I said, he gave me everything I needed whenever I needed so. He, we had plans of after matric I would go varsity and all that stuff so when he passed on its like wow it felt like my whole world just flashed away and I was like wow that it I'm on my own now (Derek, 24, employed).

Someone that I can talk to with, my mom, then I would definitely go to her. But other than that I would go to my aunt... cuz she's my best friend (Vee, 23, student).

It is evident from the data collected that social support structures are seen to promote and facilitate engagement in all areas of occupation, particularly work and instrumental activities of daily living.

\section{Coping Mechanisms: Escape from the real world}

Under this subtheme, the participants exhibited different coping mechanisms to facilitate engagement in social participation. Four of the five participants used music in different forms as a means to cope with social challenges arising from with living with albinism. Two out of the five participants expressed that music was used as a means to cope, and two other participants expressed that music was used as a means to engage in social participation.

The best thing that I had to do to escape from the real world was get involved in some activities, school activities like poetry and music and so forth (Derek, 24, employed).

I just do music as a hobby, something to take my mind off things (Bob, 3I, employed).

I go to Maskandi Festivals (music festival). I meet up with my friends from Maskandi (Vee,23, student).

In terms of coping with environmental barriers, it was noted that all the participants used protective gear such as sunglasses, long sleeved clothes, hats and sunscreen in order to protect them from the sun's direct glare.

So I normally bring sunglasses, sunscreen and a hat. I try to get something like a cover up so my shoulders, my arms and everything is covered. I also like you know try to get the best sunscreen I can get. Some of us with albinism need an umbrella (Thandi, 23, student).

\section{Structural support: Different people need different things}

Participants indicated the supportive role that established structures played in facilitating occupational engagement. These structures included the disability unit within the university as well as technology and media. The disability unit provided two of the participants with access to online lecture notes, allowing for modification of font size through the use of technology. Media served as a platform to promote albinism awareness to the wider public, as well as to advocate for the participants and their individual needs. Participants did not indicate any structural support within the workplace.

I think it was two tutorials that I just didn't know what was going on because the tutor was writing on the board and then I went to the disabilities unit after the second one. I told them and then they emailed the tutor, and then whatever she wrote on the board she later emailed it to me (Thandi, 23, student).

Maskandi has the second biggest followers in South Africa and those people are the people that are coming from the farm, the same people that believe we are luck. Since Maskandi has such an influence, I asked him [the DJ] to make a song about people with Albinism... He did it and after that a lot of people were like ....'Haibo, people really kill you for muti? And you're like 'Ja'; cos they heard it from the song (Vee, 23, student).

\section{Reasonable accommodations: I can't read print that is too small or too light}

Four of the five participants noted that accommodations made in various educational institutions such as enlarging the font size, providing printed materials, computers with software that catered to their eyesight needs, and lectures being audio taped, facilitated and supported their ability to fully engage in education. While the educational sector provided reasonable accommodations, one participant who was employed within the workplace noted he was able to perform his work-specific role to satisfactory standards, while two participants identified that the workplace environment limited their potential for growth, owing to the lack of reasonable accommodations provided.

See at school everything was enlarged so we didn't have to wear magnifying glasses so it was just catered for (Thandi,23, student).

We have like a different LAN [local area network] where our computers like are just adjusted to be where you want it to be (Thandi,23, student).

Studying was basically online, most lectures were audiotaped (Bob,3I, employed).

I normally took the notes from the teacher and wrote it down after we done writing on the board (Bob, 31 , employed).

\section{DISCUSSION}

A positive sense of self emerged as individuals acknowledged that the way in which they felt about themselves and the way in which they translated this self-perception, was the way in which society perceived them. All participants, except one, displayed acceptance towards their condition, and used their positive identity as a catalyst to facilitate occupational engagement. Me and them emerged as a differential perception of the self among participants, whose selfperception reflected self-stigma. However, only one participant indicated that his stigmatising view of himself impacted on social participation negatively.

Upbringing played a large role in contributing to the development of a positive sense of self, as depicted by the participants who emphasised the development of self-acceptance as originating from parental acceptance. These findings are supported by Christianson 
et al. ${ }^{4}$ who emphasised the role of the family in the development of a good self-concept and, ultimately, a well-established self-esteem. Parental acceptance and support facilitated the participants' engagement in extra-mural activities that instilled fundamental life skills and values, which underpinned their positive sense of self and identity. In contrast to these findings, Wan-Kee-Cheung ${ }^{16}$ and a WHO report " emphasised the direct link between stigma, discrimination and social withdrawal, which negatively affected the individuals' ability to engage in socially-orientated activities.

An important factor that needed to be noted was the age of the literature, as contemporary articles depicted a positive sense of self, whilst older articles reflected individuals with albinism who were defined by their physical appearance and the associated societal stigmatisation ${ }^{10,16}$. Findings from this study relating to a positive sense of self were supported by Christianson et al. ${ }^{4}$, which may be attributed to the attitudes and perceptions of the millennial generation, which is considered open-minded, liberal and deviating from traditional beliefs ${ }^{17}$. This study found that a positive sense of self culminated in the conclusion that acceptance stemmed from the understanding that physical attributes associated with OCA were not self-defining, and that identity was based on the way in which one conducted oneself.

Physical limitations prevailed as one of the key contributing challenges to occupational engagement, underpinning environmental barriers and mythological beliefs. Within this study participants confirmed their visual impairments impacted on their performance in various areas of occupation, from childhood to adulthood. Franklin et $\mathrm{al}^{18}$ emphasised the magnitude of the effect of visual impairments on scholastic performance, as students were not given access to the necessary reasonable accommodations within mainstream schools. The release of the Education White Paper $6^{19}$, which forefronts inclusive education, directly contradicted the individuals' experiences within the mainstream schooling system. This highlighted the inability of mainstream schools to accommodate for individuals with albinism, despite constitutional law. The occupational justice frame of reference acknowledges the contribution of policies, both international and national, to occupational engagement. According to this frame of reference, policies can either facilitate or limit participation in occupational engagement. In this study it is noted that White Paper $6{ }^{19}$ policy was set in place to facilitate occupational engagement and reduce occupational deprivation, however, the manner in which the policy has been implemented does not mitigate the barriers arising from physical barriers of albinism. Owing to the challenges attributed to physical barriers in people with albinism, these individuals are usually placed within "special schools", despite the potential for structural adaptations that would facilitate learning within mainstream schools ${ }^{19}$.

These physical limitations were shown to impact the participants throughout various stages of their life. The workplace was another context in which the participants' physical limitations acted as a barrier as they were unable to perform their work-specific role to satisfactory standards. These findings were supported by Mutasa ${ }^{20}$ who found that a work environment that is not holistically supportive of the needs of their employees limits the employees from achieving their maximum potential.

Limitations to accessing the physical environment included the participants' extreme skin sensitivity to the sun, which was found to have significant occupational implications in the areas of social participation and leisure. This finding was emphasised by Matshovhana and Mulibana ${ }^{21}$ who stated that the utilisation of free time was affected as there was a range of challenges that individu- als with this condition encountered while participating in outdoor recreation activities. Despite these challenges, all the participants made attempts to engage in their preferred occupations.

Awareness of the condition and the effect of the sun on their skin did not necessarily mean participants avoided the outdoors completely, as the majority of the participants found a way to mitigate the effect that the sun had on their skin, as opposed to only staying indoors ${ }^{22}$. The majority of the participants used sunscreen or protective clothing when taking part in activities that exposed them to direct sunlight. Kagashe et al..$^{22}$ found in their study that people with albinism made use of sunscreen as a means to cope with the effects of the sun on their skin, when they engaged in occupations outdoors which exposed them to the sun's direct glare. However, in this study, participation in outdoor activities was limited to activities of daily living and social participation. Participants verbalised reservations when applying for a job, or engaging in sporting and leisure activities that required them to be in direct sunlight for extended periods of time.

Additionally, myths and beliefs have well-established ties with albinism, particular to traditions and rituals within community settings. A lack of knowledge emerged as a concept that underpinned the correlation between the condition and the pervasive mythical beliefs. Myths and beliefs infiltrated into social perceptions of the participants who were called derogatory names when in social and community settings ${ }^{2,8}$. Participants expressed that their greatest fear was associated with mythical beliefs, which emanated from albinism and traditional rituals. This established fear was particular to interaction within open community spaces, where participants felt most vulnerable, requiring accompaniment from other people.

The emergence of vulnerability correlated with the fact that mythical beliefs associated with albinism originated from the belief that individuals with albinism bring good luck ${ }^{10}$. This statement was brought to light by the implications of mythical beliefs and societal interactions from a point of admiration. While the perception of luck appeared to have monetary gain for individuals with albinism, the potentially fatal repercussions associated with these mythical beliefs, such as the killing of individuals with OCA for body parts that are used in traditional medicine, could not be ignored ${ }^{9}$.

Occupational implications associated with myths and beliefs extended into the workplace in the form of stigma and discrimination ${ }^{6}$, in particular to the provision of job opportunities, as perceived by the participants. Participants indicated that job opportunities were limited to learnerships as opposed to permanent employment, which they perceived as unjust. South Africa implemented the Green Paper on Human Resource Development as a means of developing the skill set of South Africans who were perceived as disadvantaged, providing them with an opportunity to integrate into the workforce ${ }^{23}$. Whilst learnerships were perceived as discriminatory from the perception of the participants, legislation indicated that learnerships were in fact an empowerment strategy ${ }^{24}$.

Findings from this study highlighted components of various support systems such as the media, support groups, and the use of technology. Supportive organisations, such as the Albinism Society of South Africa as well as the university's disability unit, were established to facilitate occupational engagement ${ }^{24}$, however four out of five participants indicated that they did not utilise these organisations as occupational facilitators, but rather as social platforms. One participant identified the organisation as a platform for advocacy, which benefited the participants and other individuals with albinism. This finding is contrary to a study conducted by Mutasa ${ }^{20}$, in Zimbabwe's Manicaland province, which found that all the respondents in their 
study sought support for occupational engagement from organisations for people with albinism.

In terms of social support, it was found that facilitators to occupational engagement in this context came from friends, work and church colleagues, as well as family members ${ }^{25}$. Majority of the participants in this study noted that their family gave them comfort and support that helped them fully engage in their occupations. Mutasa $^{20}$ also found that participants in their study had supportive families who understood their conditions. According to their study, family support as a means of social support was a facilitator to occupational engagement. This echoes the findings of this study, as the majority of the participants expressed that a relationship with family members encouraged and supported safe engagement in occupations ${ }^{20}$.

Mutas $\mathrm{a}^{20}$ found that the participants in their study used religious affiliation as a coping mechanism, as attending church brought a sense of community. Their study found that religious leaders played a major role in educating the community on albinism and reducing the stigma and discrimination that people with albinism faced ${ }^{20}$. In this study, the findings were somewhat surprising, that even though the majority of the participants were members of a religious community, only one participant considered the church as a facilitator to occupational engagement. However, the findings in this study noted that the majority of the participants used music as a coping mechanism, in addition to social support, structural support and reasonable accommodations, which could not be refuted or substantiated by literature as there is little to no research on music as a coping mechanism in people with albinism.

\section{Limitations of the study}

Limitations of the study included a small sample size, as the study included only five participants. All participants were African race and resided with the eThekwini district. Addressing these limitations in future research would improve the generalisability of the findings.

\section{CONCLUSION}

The findings from this study identified various barriers to occupational engagement that were rooted in congenital characteristics associated with OCA. A pivotal finding was the sense of self that emerged as a new finding, as existing literature found people with this condition tended to be withdrawn and had a negative selfimage $^{8}$. A positive sense of self underpinned facilitation in occupation, as participants utilised foundational values developed through parental acceptance and extramural activities. In conjunction with a positive sense of self, social support, structural support and reasonable accommodations facilitated occupational engagement. In the face of barriers to occupation, participants utilised coping mechanisms as a means of facilitating engagement in various areas of occupation.

Therapists and Disability Rights groups need to advocate that individuals with albinism be provided with SPF50 sunscreen, as opposed to SPF I 5 (which they are currently receiving at their local clinics) to enable them to partake in outdoor activities as SPF50 protects the individual from UVB rays. This will enable safer participation when engaging in social participation and leisure in outdoor spaces. Labour practitioners and occupational therapists need to conduct work visits to ensure and advocate for reasonable accommodations for people with disabilities, including people with OCA. Occupational therapists should create awareness around albinism through the provision of education to the eThekwini District society to ensure better understanding of the condition which will result in better occupational engagement for individuals with albinism.

\section{REFERENCES:}

I. Hong ES, Zeeb H, Repacholi MH. Albinism in Africa as a public health issue. BMC public health. 2006 Dec; 6(I): 212.

https://doi.org/I0.I I86/I47I-2458-6-2I 2.

2. Baker C, Lund P, Nyathi R, Taylor J. The myths surrounding people with albinism in South Africa and Zimbabwe. Journal of African Cultural Studies. 2010 Dec I; 22(2): 169-8I. https://doi.org/10.1080//36968/5.2010.49|412

3. Blankenberg N. That rare and random tribe: Albino identity in South Africa. Critical Arts. 2000 Jan I; 14(2): 6-48.

https://doi.org/10.1080/0256004008531008।

4. Christianson AL, Pooe-Monyemore MB, Mavundla TR. The experience of people with oculocutaneous albinism. Health SA Gesondheid. 201 I Jan I; I7(I): I-8.

https://dx.doi.org/10.4102/hsag.v17il.592

5. Wilcock AA, Hocking $C$. An occupational justice perspective of health. An occupational perspective of health. 3rd ed. New Jersey: Slack Incorporated. 2015: 390-419.

https://doi.org/10.1080/01924780903295804

6. Montoliu L, Grønskov K, Wei AH, Martínez-García M, Fernández A, Arveiler B, Morice-Picard F, Riazuddin S, Suzuki T, Ahmed ZM, Rosenberg T. Increasing the complexity: new genes and new types of albinism. Pigment cell \& melanoma research. 2014 Jan; 27(I): I I-8. https://doi.org/10.1 I I I/pcmr.12167

7. Cavico FJ, Muffler SC, Mujtaba BG. Appearance Discrimination, Lookism And Lookphobia In The Workplace. Journal of Applied Business Research (JABR). 2012 Aug 2I; 28(5): 79I-802. https://doi.org/10.1 108/02610151311305632

8. Msomi V.D. Stark White: Experiences of Learners with Albinism (LWA) in Primary and Secondary Schools in the UMlazi District (Doctoral dissertation, University of KwaZulu-Natal, Durban). https://hdl.handle.net//04/3/I2667

9. Brilliant $\mathrm{MH}$. Albinism in Africa: a medical and social emergency. International health. 2015 Jul I; 7(4): 223-5.

https://doi: $10.1093 /$ inthealth/ihv039

10. Phatoli R, Bila N, Ross E. Being black in a white skin: Beliefs and stereotypes around albinism at a South African university. African Journal of Disability. 2015; 4(I). https://doi:10.4I02/ajod.v4il.106

I I. World Health Organization. The world health report 2006: Working together for health. World Health Organization; 2006 (accessed 23.4.2019) Available at: https://www.who.int/whr/2006/en/.

12. Marshall C, Rossman GB. Designing qualitative research. Sage publications; 2014 Dec 16.

13. Patton MQ, Cochran M. A guide to using qualitative research methodology. 2002.

14. Connelly LM. What is phenomenology? MEDSURG Nursing. 2010 Mar I; 19(2): 127.

15. Braun V, Clarke V. Using thematic analysis in psychology. Qualitative Research in Psychology. 2006 Jan I; 3(2): 77-I0I.

16. Wan-Kee-Cheung N. The voices of albinism. Masters thesis, Concordia University. 200I (accessed 5.4.2019) Available at https://spectrum.library.concordia.ca/ 1667/

17. Swanzen R. Facing the generation chasm: the parenting and teaching of generations $Y$ and $Z$. International Journal of Child, Youth and Family Studies. 2018 May 15; 9(2): 125-50. https://doi.org/10.18357/ijcyfs92201818216

18. Franklin A, Lund P, Bradbury-Jones C, Taylor J. Children with albinism in African regions: their rights to 'being'and 'doing'. BMC 
International Health and Human Rights. 2018 Dec; 18(I): 2.

https://doi.org/I0.1 I86/sI29|4-018-0144-8

19. Department of Education. Education white paper 6: Special needs education: building an inclusive education and training system. Department of Education; South Africa 200 I.

20. Mutasa FL. An investigation into the psychosocial implications of Oculocutaneous Albinism. a case study of Manicaland Albino Association. Master of Social Work Dissertation, Harare: University of Zimbabwe. 2014 (accessed 23.4.2019) Available at: https://ir.uz.ac.zw/xmlui/handle// 0646//279

21. Matshovhana K, Mulibana PK. Challenges faced by learners with albinism in active recreation activities at Tshilidzini Special School, Thohoyandou, South Africa. African Journal for Physical Health Education, Recreation and Dance. 2014 Dec I; 20(Supplement I): I-9.

22. Kagashe GA, Maregesi SM, Mnyenye A. Availability knowledge and use of sunscreen Products by people with albinism in Dar Es Salaam Region-Tanzania. International Research Journal of Pharmaceutical and Applied Sciences 2013; 3(6): 70-74

23. Chili NA. Economic growth and employment in South Africa: A critical policy analysis Master of Arts in Economics, University of Johannesburg. 2000 (accessed 6.8.2019). Available at: https://ujcontent.uj.ac.za/vital/access/manager/Repository/uj:2828?site_name $=$ GlobalView\&view $=$ null\&f0 $=s m$ subject\%3A\%22South+Africa+-

+ Economic + policy.\%22\&sort $=$ null

24. Matshedisho KR. Experiences of disabled students in South Africa: Extending the thinking behind disability support. South African Journal of Higher Education. 2010; 24(5): 730-44.

25. House JS, Umberson D, Landis KR. Structures and processes of social support. Annual Review of Sociology. 1988 Aug; 14(I): 293318. https://doi.org//0.1146/annurev.so.14.080188.001453

\section{AUTHOR CONTRIBUTIONS}

Lara Mather was designated by the research group to compile the research article. She as well as Henna Nathoo, Fortune Feresu, Nhlanhla Dlamini, Trinity Ncube and Zuleika Patel conceptualised and conducted the research and contributed to the article

Thavanesi Gurayah and Deshini Naidoo were the primary and co-supervisors of the research process, reviewing all written content.

*Corresponding Author

Lara Mather

Email: Laramather1995@gmail.com 